\title{
Der Geschäftsbericht zum Jahr 2008 liegt vor
}

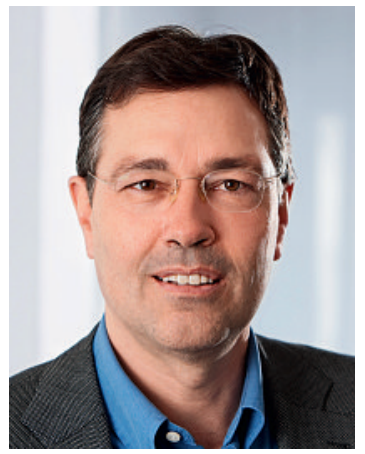

Daniel Herzog
Als Beilage zur heutigen Ausgabe der Schweizerischen Ärztezeitung finden Sie den Geschäftsbericht 2008 der FMH. Bei seiner Lektüre werden Sie feststellen, wie vielfältig und intensiv das Wirken der FMH im Berichtsjahr war. An der politischen Front galt es, die Angriffe auf den Kontrahierungszwang abzuwehren, was dank der konzertierten Vorgehensweise der FMH zusammen mit anderen blauen Berufsverbänden eindrücklich gelang: Mit einer Mehrheit von fast 70\% lehnte das Schweizer Volk am 1. Juni 2008 den Verfassungsartikel ab, der die Macht der Krankenkassen erheblich ausbauen wollte. Politische Initiativen in Richtung Vertragsfreiheit dürften es damit in nächster Zeit deutlich schwerer haben.

\section{Die Ärzteschaft hat die Angriffe auf den Kontrahierungszwang erfolgreich abgewehrt}

Spannend und erfolgreich verliefen 2008 auch unsere Projekte: Die Health Professional Card steht zum Beispiel dank der umfangreichen Vorarbeiten kurz vor der Auslieferung und aus dem Ressort Aus-, Weiter- und Fortbildung ist das verselbständigte Schweizerische Institut für Weiter- und Fortbildung geworden. Über diese und alle weiteren Projekte finden Sie im Geschäftsbericht eine gute Übersicht.

Auf organisatorischer Ebene stand 2008 die Gesamterneuerungswahl - und gleichzeitige Verkleinerung - des Zentralvorstands im Vordergrund. Von den ehemals elf Mitglie- dern sind noch fünf im neuen Zentralvorstand vertreten; vier Mitglieder hat die Ärztekammer neu gewählt. Der neue Zentralvorstand kann weiterhin auf das bestehende Wissen seiner Mitglieder zurückgreifen und nun dank seiner schlankeren Struktur noch effizienter arbeiten.

\section{Die FMH verzeichnet einen Mitglieder-}

\section{zuwachs von rund 2,7 Prozent}

Die ersten Monate seiner Amtszeit hat der neue Zentralvorstand unter anderem dazu genutzt, die Strategie für die Legislaturperiode 2008-2012 zu entwickeln, die die ausserordentliche Ärztekammer vom Dezember 2008 verabschiedet hat. Damit besteht nun ein Handlungsrahmen, der dem Zentralvorstand die Richtung vorgibt und gleichzeitig dessen Aktivitäten legitimiert.

Die FMH ist offensichtlich eine attraktive Berufsorganisation. Anders lässt sich der Mitgliederzuwachs um rund 2,7\% auf 34547 per Ende 2008 nicht interpretieren. Auch scheint die Nachfrage nach Facharzttiteln und Schwerpunkten ungebrochen, resultiert hier doch ebenfalls ein starker Zuwachs.

Finanziell blickt die FMH erneut auf ein gutes Jahr zurück und dies, obwohl die Mitgliederbeitragshöhe gegenüber dem Vorjahr geringer war. Sie schliesst mit einem komfortablen Ertrag ab, wobei dieser in erster Linie durch die erhöhte Nachfrage nach Facharzttiteln und Schwerpunkten im Bereich Aus-, Weiter- und Fortbildung erzielt wurde.

Alles in allem ein erfolgreiches Jahr. Überzeugen Sie sich selbst - und lassen Sie dabei die faszinierende Welt der Mikroorganismen auf sich wirken, die in diesem Jahr das Thema der Bildwelt darstellt.

Ich wünsche Ihnen eine spannende Lektüre!

Daniel Herzog, lic. iur., MHA, Generalsekretär der FMH 